\title{
O ACESSO À JUSTIÇA COMO DIREITO AO MÉRITO PARTICIPADO NAS AÇÕES COLETIVAS
}

\section{ACCESS TO JUSTICE AS A RIGHT TO MERIT PARTICIPATED IN COLLECTIVE ACTIONS}

Fabrício Veiga Costa

\section{Resumo}

O acesso à Justiça no Estado Democrático não se limita ao direito de se dirigir ao judiciário, visto que se efetiva quando é assegurado a todos interessados o direito de debater amplamente os pontos controversos da demanda. Nesse cenário, a Teoria das Ações Coletivas como Ações Temáticas ressignifica o atual modelo representativo que regula as ações coletivas no Brasil (rol taxativo de legitimados ativos que exclui o cidadão), ao permitir que todos os interessados sejam co-autores da formação participada do mérito processual, assegurando-se, assim, o acesso efetivo à justiça, e prevenindo o cerceamento de defesa.

Palavras-Chave: Acesso à Justiça; Mérito Processual; Sistema Participativo; Ações Coletivas; Teoria das Ações Temáticas.

\begin{abstract}
Access to justice in the Democratic State is not limited to the right to address the judiciary, since it is effective when all parties concerned are assured the right to debate the controversial points of the complaint in large part. In this scenario, the Theory of Collective Actions as Thematic Actions re-signifies the current representative model that regulates collective actions in Brazil (a taxative list of legitimized assets that excludes citizens), by allowing all stakeholders to be co-authors of the participatory formation of merit Process, thus ensuring effective access to justice, and preventing the defense curtailment.
\end{abstract}

Key words: Access to Justice; Procedural merit; Participative System; Collective Actions; Theory of thematic actions. 


\section{Introdução}

O objeto da presente pesquisa cientifica é investigar criticamente o estudo do acesso à justiça no Estado Democrático de Direito viabilizado a partir do amplo debate participado do mérito processual nas ações coletivas. Especificamente pretende-se demonstrar que o direito de ação, visto sob a ótica da processualidade democrática, deverá legitimar a participação de todos os interessados (sujeitos afetados juridicamente pelos efeitos do provimento final) na definição e amplo debate participado das questões que integram o objeto da lide. A atual sistemática adotada pela processualística brasileira estabelece que somente participarão do debate do mérito processual aqueles sujeitos autorizados pelo legislador ou pelo magistrado, caracterizando-se, assim, um modelo de processo autocrático e incompatível com o processo constitucional democrático.

Restringir o debate do mérito processual a uma assembléia de especialistas (magistrado, perito, Ministério Público) e aos sujeitos autorizados aprioristicamente pelo legislador ou juiz, excluindo-se de forma peremptória todos os demais sujeitos afetados juridicamente pelos efeitos do provimento final, caracteriza uma forma de limitar o acesso a justiça? Esse é o questionamento inicial proposto para ser debatido ao longo do respectivo estudo, de modo a evidenciar que o modelo de processo coletivo brasileiro vigente pauta-se no sistema representativo. Ou seja, o rol de legitimados à propositura da ação civil pública é taxativo, exclui o cidadão e impossibilita a participação dos interessados no debate do mérito processual, limitando-se, assim, o acesso democrático à justiça.

Nesse sentido, torna-se necessário ressignificar epistemologicamente o estudo do mérito processual nas ações coletivas, compreendendo-o sob a ótica do sistema participativo, expressamente previsto no artigo $1^{\circ}$ da Constituição brasileira de 1988. Definir os legitimados ativos que poderão debater democraticamente o mérito processual nas ações coletivas a partir do objeto da ação proposta é uma forma de superar a clássica e hermética concepção adotada pelo legislador brasileiro, que define previamente aqueles sujeitos que integrarão a relação processual. Para isso, utilizar-se-á como marco teórico a Teoria das Ações Coletivas como Ações Temáticas, de autoria do jurista mineiro Vicente de Paula Maciel Júnior, que propõe o estudo dos legitimados ao debate meritório nas ações coletivas a partir do objeto da demanda.

O acesso à justiça no Estado Democrático de Direito passa diretamente pelo entendimento do processo como um lócus de discursividade ampla e participada das questões de mérito por todos os interessados difusos na construção do provimento final. A matéria de 
mérito não pode ser apenas aquela exclusivamente definida pelo sujeito que propôs a ação civil pública. O objeto inicialmente definido pelo autor da ação deverá englobar todos os outros temas a ele pertinentes, ressaltando-se que a realização de audiências públicas é uma das formas de democratizar o debate do mérito nas ações coletivas.

A escolha do tema justifica-se pela sua relevância fático-social e jurídica, tendo em vista que legitimar o modelo de processo coletivo que oportuniza o debate do mérito apenas àqueles sujeitos escolhidos pelo legislador ou juiz constitui uma forma de limitar o acesso à justiça, tendo em vista que os sujeitos afetados pelos efeitos do provimento final ficam alheios a sua construção democrático-participada.

Quanto à metodologia, utilizou-se da pesquisa teórico-bibliográfica, mediante o estudo de autores clássicos que debatem o mérito processual na perspectiva do processo civil e coletivo. A utilização de análises temáticas, teóricas, interpretativas e comparativas foi essencial ao estudo crítico do objeto da pesquisa, uma vez que foi possível apresentar novas proposições teóricas no que atine ao estudo do mérito processual participado nas ações coletivas. Por meio do método indutivo, partiu-se do estudo do sistema representativo como fundamento regente do atual modelo de processo coletivo brasileiro, ampliando-se o espectro de análise da proposta de pesquisa de modo a evidenciar que ressemantizar as ações coletivas a partir do sistema participativo é um meio de assegurar democraticamente o acesso à justiça.

\section{A gênese do mérito processual na perspectiva do processo civil e as contribuições cientificas da doutrina brasileira.}

A proposta específica do primeiro capítulo é justamente estudar e demonstrar que os critérios utilizados pelos autores clássicos para definir o mérito no processo individual é utilizado como referencial teórico para a sedimentação do modelo de processo coletivo adotado pelo Brasil, especialmente quando se analisa, por exemplo, a Lei de Ação Civil Pública, que ao restringir o rol de legitimados processuais ativos a sua propositura (excluindo-se o cidadão) certamente demonstra a opção pelo sistema representativo.

O conceito de mérito do processo civil, trabalhado pelos autores analisados no presente capitulo, é a base de todo o sistema representativo adotado no modelo de processo coletivo brasileiro vigente, haja vista que o legislador é quem definiu abstratamente aquelas pessoas 
consideradas legitimadas à propositura das ações coletivas, excluindo-se, na maioria das vezes o cidadão.

A relação existente entre o mérito do processo civil e o sistema representativo resta evidente na limitação dos sujeitos que participarão da formação do mérito, ou seja, tanto no processo civil quanto no modelo de processo coletivo adotado atualmente no direito brasileiro é o legislador quem define os legitimados a propositura da ação coletiva, à definição da matéria de mérito e a participação no debate da matéria de mérito no âmbito processual. Isso implica em limitação na participação dos interessados na formação do mérito, algo que se pretende demonstrar ao longo de todo a pesquisa por meio da apresentação dos fundamentos teóricocientíficos utilizados como parâmetro à compreensão de que a formação participada do mérito nas ações coletivas é um meio de democratizar o acesso à justiça a todos os sujeitos que sofrerão os efeitos jurídicos do provimento final.

Tanto no processo civil quanto no processo coletivo brasileiro vigente não se vislumbra a formação participada do mérito, pelo fato de não haver abertura que oportunize isonomicamente a participação de todos os interessados na definição da matéria de mérito e, também, na construção do mérito como conseqüência do debate amplo das questões fáticojurídicas suscitadas pelas partes. É nessa seara que se inicia o estudo específico do tema, ressaltando-se que etimologicamente a palavra mérito vem do latim meritum, cuja significação é "merecimento, aptidão, superioridade, bom serviço"1 (BASTOS, 1928, p. 912).

A compreensão dos fundamentos científicos do mérito processual sempre foi, e ainda é, objeto de profundas e de hesitantes discussões jurídicas, tendo em vista o seu caráter polissêmico e também a ausência de critérios de cientificidade para o seu entendimento ${ }^{2}$.

Essa indefinição teórica acerca do mérito decorre da sua proximidade com o conceito da causa de pedir, visto processualmente pela Escola Instrumentalista ${ }^{3}$ como a fundamentação

\footnotetext{
${ }^{1}$ Importante ressaltar que pela pesquisa ora desenvolvida não houve, a partir de 1928, relevante contribuição filológica com relação ao conceito de mérito.

2 [...] Demonstrando a promiscuidade do legislador na utilização da expressão, em caminho seguido por outros processualistas, Cândido Rangel Dinamarco mostrou que o legislador brasileiro, na Exposição de Motivos do Código de Processo Civil, conferiu à palavra l"lide", dentre outros, o significado de "mérito", o mesmo ocorrendo, quase sempre, ao longo do mencionado diploma legal. Assim, expressões como "julgamento antecipado da lide" (v.g. nomenclatura utilizada na seção em que se encontra o artigo 330), "julgar total ou parcialmente a lide" (artigo 468), litisconsórcio por "comunhão de direitos ou de obrigação relativamente à lide" (artigo 46, inciso I), " conhecimento da lide" (artigo 110) e outras tantas são exemplos da utilização da expressão lide com sinônimo de mérito. (MADEIRA, 2010, p. 109).

${ }^{3}$ Todas as vezes que for mencionado ao longo dessa pesquisa a expressão "Escola Instrumentalista de Processo" ou "Escola Paulista de Processo" pretende-se fazer uma remissão aos estudos científicos e sistematizados especialmente pelos professores e pesquisadores da Universidade de São Paulo, e mais recentemente da Pontifícia Universidade Católica de São Paulo, especialmente os professores doutores Cândido Rangel Dinamarco, Alfredo
} 
fático-jurídica da pretensão deduzida em juízo e, nessa perspectiva, o mérito processual restringir-se-ia à análise dessas peculiaridades fático-jurídicas e/ou apenas jurídicas da pretensão deduzida em juízo.

A ideologização e a dogmatização do tema mostra-se na dificuldade dos estudiosos quanto a sua conceituação e também na promiscuidade como o tema é abordado. Tal afirmação justifica-se pela ausência de cuidado dos pesquisadores em diferenciar sistematicamente o mérito, a pretensão, a lide, a demanda, o objeto ${ }^{4}$, a causa de pedir próxima e remota. $\mathrm{O}$ que se pretende com a presente pesquisa é inicialmente teorizar o estudo do mérito a partir do processo individual para, assim, estabelecer critérios científicos suficientes ao seu entendimento no âmbito do processo coletivo.

O estudo da gênese do mérito processual justifica-se pela proximidade do tema com a matéria de fato $^{5}$ e a matéria de direito, consideradas o pressuposto para o entendimento de conceitos fundamentais do Direito Processual e, por conseguinte, requisitos indispensáveis à análise do mérito da pretensão nos ditames expostos pelo legislador do Código de Processo Civil brasileiro vigente. A causa de pedir, o objeto da lide, a pretensão e a própria lide são institutos cujo entendimento condiciona-se à teorização do que seja matéria de fato e matéria de direito. O que temos nos estudos desenvolvidos até então é que a matéria de fato e a matéria de direito, como temas do Direito Processual, são vistas sob a ótica ideológica, ou seja, existe uma ínsita relação entre elas e mérito processual. Tal relação encontra-se claramente estruturada

\footnotetext{
Buzaid, Kazuo Watanabe e Ada Pelegrini Grinover, cujos estudos científicos no âmbito do direito processual são relevantes e foram desenvolvidos a partir das proposições teóricas de Enrico Tullio Liebman.

${ }^{4}$ Objeto litigioso, pois, é conceito menor do que objeto do processo. Em conclusão, diz que o objeto litigioso "é o mérito, assim entendido o pedido do autos formulado na inicial ou nas oportunidades em que o ordenamento jurídico lhe permita ampliação ou modificação; o pedido do réu na reconvenção; o pedido do réu formulado na contestação, nas chamadas ações dúplices; o pedido do autor ou do réu nas ações declaratórias incidentais (sobre questões prejudiciais); o pedido do autor ou do réu contra terceiro na denunciação da lide; o pedido do réu no chamamento ao processo; o pedido do terceiro contra autor e réu, formulado na oposição. Em suma, é o pedido que, na opinião de Sydney Sanches, caracteriza o objeto litigioso (DINAMARCO, 1987, p. 213).

${ }^{5} \mathrm{O}$ artigo 330 do Código de Processo Civil vigente (CPC 1973) estabelece: "O juiz conhecerá diretamente o pedido, proferindo sentença: I- quando a questão de mérito for unicamente de direito, ou, sendo de direito ou de fato, não houver necessidade de produzir prova em audiência; II- quando ocorrer a revelia". (BRASIL, Código Civil, Comercial, Processo Civil e Constituição Federal, 2008, p.642). Nesse dispositivo legal verifica-se a relação intrínseca entre o mérito e a matéria de fato. Pelo que se extrai da leitura do dispositivo o legislador limitou o instituto do mérito às alegações de fato e de direito, inerentes à pretensão, cuja apreciação dar-se-á a partir do exercício da jurisdição pelo julgador, que quando da análise do mérito excluirá qualquer participação das partes (demandante, demandado e demais sujeitos juridicamente interessados na pretensão) na construção do mérito. Assim, pode-se afirmar que o conceito de mérito adotado pelo legislador do Código de Processo Civil de 1973 advém de uma concepção autoritária de processo e do entendimento da jurisdição enquanto sacerdócio e poder exercido pelo julgador.
} 
a partir dos conceitos de sentença terminativa ${ }^{6}$ (sentença que extingue o processo sem julgamento do mérito), de sentença definitiva (sentença em que o julgador garante a resolução do mérito da pretensão deduzida) e também no instituto do Julgamento Antecipado da Lide.

Pode-se afirmar que hoje o entendimento jurídico-científico comum entre os processualistas é de que o mérito processual percorre a essência da situação processual instituída a partir do poder inerente à jurisdição. Ou seja, o enfrentamento do mérito é visto como uma prerrogativa do julgador, e não como um direito das partes.

A ausência de um conceito construído e pacificado sobre o mérito é o que garante criticamente as reflexões cientificas propostas na presente pesquisa. Para Candido Rangel Dinamarco "o mérito é o complexo das questões materiais que a lide apresenta" (DINAMARCO, 1996, p. 200). Giuseppe Chiovenda compreende o mérito a partir do conceito de demanda. Nesse sentido é oportuna a citação de Chiovenda exteriorizando o seu entendimento sobre o que é demanda: "é o ato pelo qual a parte, afirmando existente uma vontade contrata de lei, que lhe garante um bem, declara querer que essa vontade se atue, e invoca para esse fim a autoridade do órgão jurisdicional”(CHIOVENDA, 1969, p. 297). Verifica-se, previamente, que para Chiovenda o mérito reside na demanda, tendo em vista ser a sentença o provimento estatal que reconhece ou não a demanda do jurisdicionado. Oportuno esclarecer que a demanda é vista aqui como a pretensão, ou seja, como uma narração reivindicativa de um direito materializado na petição inicial. Nesse sentido é ressalta a contribuição de Kazuo Watanabe: “demanda é fato estritamente processual e constitui veículo de algo externo ao processo e anterior a ele, algo que é trazido ao juiz em busca de um remédio que o demandante quer" (WATANABE, 1987, p. 731).

Calamandrei deixa explícito em sua obra o caráter dialético ${ }^{7}$ da relação processual, que pode ser vista como um espaço de debate e de discussão das partes acerca da pretensão e do

\footnotetext{
${ }^{6}$ Grosso Modo, pode-se dizer que haverá julgamento conforme o estado, sem que se aprecie o mérito, se o juiz verificar de oficio ou se convencer da alegação de uma das partes, quanto à inexistência de pressuposto processual ou de quaisquer das condições da ação, ou quando houver a presença de pressuposto processual negativo. (WAMBIER, 2005, p. 420)

${ }^{7}$ O processo não é somente uma série de atos que devem se suceder numa determinada ordem estabelecida pela lei (ordo procedendi), senão que é também, no cumprimento desses atos, um ordenado alternar de várias pessoas (actus trium personarum), cada um a das quais, nessa série de atos, deve atuar e falar no momento preciso, nem antes nem deposi, do mesmo modo que na recitação de um drama cada ator tem que saber "entrar" a tempo para sua intervenção, ou numa partida de xadrez têm os jogadores que se alternar com regularidade no movimento de suas peças. Mas a dialeticidade do processo não consiste somente nisto: não é unicamente o se alternar, numa ordem cronologicamente preestabelecida, de atos realizados por distintos sujeitos, senão que é a concatenação lógica que vincula cada um desses atos ao que o precede e ao que o segue, o nexo psicológico em virtude do qual cada ato que uma parte realiza no momento preciso, constitui uma premissa e um estímulo para o ato que a contraparte poderá realizar imediatamente depois. O processo é uma série de atos que se cruzam e se correspondem
} 
mérito processual. Talvez a grande contribuição científica do autor encontra-se no sentido de reconhecer que a relação processual validamente constituída entre as partes legitima a oportunidade do autor e do réu atuarem de forma mais dinâmica e direta na construção do mérito. Percebe-se a preocupação de colocar autor e réu numa posição menos subserviente, mais autônoma e mais ativa em relação à autoridade do julgador, o que representa uma das características típicas da obra de Calamandrei.

O estudo do objeto da presente pesquisa na obra de Carnelutti justifica-se pela necessidade de demonstração de que o entendimento acerca do mérito processual ainda continua adstrito à matéria de fato e de direito trazidas pelas partes ao processo para integrar a lide, ou seja, mérito em Carnelutti são as questões de fato e de direito que integram o conflito de interesse litigioso deduzido em juízo. O julgamento de mérito ocorre quando o juiz adentra às questões que integram a pretensão litigiosa deduzida, ressaltando-se que a definição dessas questões a serem discutidas é uma prerrogativa exclusiva das partes (autor e réu) e que sua apreciação é uma atribuição exclusiva do juiz (CARNELUTTI, 2004).

O pensamento científico do processualista italiano Enrico Tullio Liebman é de extrema relevância para o estudo do objeto da presente pesquisa, haja vista que ratifica o entendimento preconizado anteriormente pelos autores estudados, de que o mérito processual consiste na análise unilateral, pelo juiz, da matéria e das questões de fato e de direito alegadas pelas partes (autor e réu) em juízo, não se preocupando em diferenciar mérito processual de matéria de mérito. É visível na obra de Liebman a reprodução do sistema representativo, considerado o referencial para modelo do processo coletivo brasileiro vigente, em que somente está legitimado a apresentar judicialmente as questões de mérito aquelas pessoas previamente autorizadas pelo legislador, excluindo-se a possibilidade dos demais interessados e afetados pelo provimento final serem inseridos processualmente na definição e no debate de outras questões relacionadas com a pretensão inicialmente deduzida em juízo. Trata-se de uma teoria absolutamente incompatível com o sistema participativo, que estabelece a base jurídica do modelo de processo coletivo democrático (LIEBMAN, 2001).

Julgar o mérito processual é manifestar-se acerca do objeto da demanda. È desse contexto que se consegue visualizar a ínsita relação existente entre mérito, lide e pedido. Os pedidos das partes (demandante e demandado) representam o objeto do processo e a delimitação dos fundamentos da lide em juízo. Demandar nada mais é do que a expectativa da parte autora

como os movimentos de um jogo: de perguntas e respostas, de réplicas e contra-réplicas, de ações que provocam reações, suscitadoras por sua parte de contra-reações. (CALAMANDREI, 1999-c, p. 225). 
ver reconhecida sua pretensão (considera-se pretensão como a narração reivindicativa expressa na petição inicial). O conflito de pedidos das partes (demandante e demandado) constitui a matéria lógica do processo e o elemento formal de seu objeto, ao passo que a dedução e a constituição do conflito de interesses em juízo representa o substrato material do processo. "Este conflito de interesses, qualificado pelos pedidos correspondentes, representa a lide, ou seja, o mérito da causa" (LIEBMAN, 2001, p. 102). A lide é um conflito de interesses moldado em juízo a partir dos pedidos das partes formulados ao juiz.

Ao longo de toda a legislação processual brasileira, especificamente o direito processual civil, verifica-se que a expressão mérito é constantemente utilizada para designar a lide, a causa de pedir (próxima e remota), a pretensão, objeto da demanda, ou seja, toda construção que o direito brasileiro desenvolveu acerca do mérito processual é no sentido de limitar sua compreensão à matéria ou as questões postas e propostas pelas partes na relação processual. A concepção que se tem sobre o mérito processual restringe-se à matéria ou as questões fáticojurídicas trazidas pelas partes (autor e demandado) para a relação processual e que servirão de parâmetro e de referencial para o julgamento dos pedidos. Esse debate científico é extremamente relevante para a presente proposta de pesquisa, tendo em vista que se busca demonstrar, ao longo de todo trabalho, que o instituto do mérito não pode se limitar à noção de que o mérito processual constitui-se apenas pelas matérias ou questões fáticas e jurídicas trazidas pelas partes na relação processual.

A democratização do acesso à justiça passa diretamente pela oportunidade conferida a todos os interessados (sujeitos que sofrem direta ou indiretamente os efeitos jurídicos do provimento final) de participarem da definição das questões debatidas no âmbito processual, superando-se o entendimento liberal de que apenas os sujeitos eleitos pelo legislador poderão integrar o espaço discursivo do processo conduzido autocraticamente por meio de decisões unilaterais e solipsistas do julgador (decididor).

A atual sistemática proposta pelo Código de Processo Civil brasileiro vigente não oportuniza a construção participada do mérito processual, tendo em vista que limita às partes (autor e demandado) o direito de trazer aos autos as questões que integrarão a lide, não oportunizando maior amplitude de participação de todos aqueles sujeitos que teriam legitimidade de participar da construção do provimento final. Além disso, o legislador do Código de Processo Civil conferiu exclusividade ao julgador no que tange à atribuição legal de proferir o despacho saneador, a fim de unilateralmente definir quais serão as questões relevantes 
à formação do mérito da demanda. Isso implica dizer que após o despacho saneador a análise e a interpretação das questões de mérito é uma prerrogativa exclusiva do julgador, sem que as partes possam influir diretamente na construção da sentença de mérito. O processo intelectivo de construção do mérito processual é uma prerrogativa exclusiva do julgador, que se utilizando do livre convencimento motivado, decide o caso concreto da forma que melhor lhe convier.

A formação participada do mérito processual somente se torna viável e plausível mediante a superação da concepção hermética e autocrática do processo visto como um instrumento da jurisdição. O processo constitucional democrático e a jurisdição devem ser vistos como instituições que buscam a implementação dos direitos fundamentais mediante a participação ampla de todos os interessados na construção dos provimentos.

\section{Mérito Processual, Acesso à Justiça e Direito de Ação}

$\mathrm{O}$ significado da expressão acesso à justiça ${ }^{8}$ tem caráter polissêmico, relativo ${ }^{9} \mathrm{e}$ conotação decorrente de uma concepção autoritária de processo que legitima o julgador a decidir solitariamente ${ }^{10}$, com possibilidade de apreciação do mérito processual a partir de análises jurídicas e metajurídicas da demanda levada pelas partes ao Judiciário. É de extrema relevância jurídica a revisitação teórica da relação existente entre mérito processual, direito de ação e acesso à justiça

Na acepção democrática proposta pela Constituição brasileira de 1988 a ação é uma palavra "integrante da expressão jurídica direito-de-ação, destinada a significar direito constitucionalizado incondicional de movimentar a jurisdição" (LEAL, 2009, p. 129). É necessário esclarecer inicialmente que o acesso ao Judiciário, conforme previsão expressa do artigo 5. Inciso XXXV da Constituição brasileira de 1988 (principio da inafastabilidade do

\footnotetext{
${ }^{8}$ Evitaremos aqui a expressão equívoca de "acesso à justiça", porque, como já esclarecemos, a palavra justiça, quando assim posta nos compêndios de direito pode assumir significados vários que, a nosso ver, perturbam a unidade semântica e seriedade científica do texto expositivo (LEAL, 2009, p. 68).

${ }^{9}$ Para Chaim Perelmann a relatividade no entendimento e na compreensão do que seja a Justiça se justifica no sentido de que não se pode convencer qualquer pessoa de que "determinada concepção de justiça é a única boa, a única que corresponde ao ideal de justiça perseguido pelo coração dos homens, sendo todas as outras apenas embustes, representações insuficientes que fornecem da justiça uma imagem falsa e servem de uma justiça apenas aparente que abusa da palavra justiça para fazer que se admitam concepções real e profundamente injustas" (BEZERRA, 2001, p. 147).

${ }^{10} \mathrm{O}$ juiz precisa estar perenemente lembrado de seu solene e patético compromisso com a justiça. Deve revelar essa consciência ao longo do processo e de sua instrução e depois, ao sentenciar, no modo como encara a prova e seus resultados, como interpreta os fatos diante do direito e os textos legais diante do objeto do processo em julgamento (DINAMARCO, 1988, p. 118).
} 
controle jurisdicional), consiste no direito das partes juridicamente interessadas participarem de forma direta da construção do mérito da demanda. $\mathrm{O}$ acesso ao Judiciário no Estado Democrático de Direito materializa-se pela implementação do debate da pretensão, pelas partes, no espaço processual, e poderem construir efetivamente o mérito.

Importante esclarecer que a construção da doutrina do acesso à justiça pela Escola Paulista de Processo é produto da ideologização da ordem jurídica justa em que o julgador é aquela pessoa legitimada a resguardar a justiça entre as partes, mediante a utilização de argumentações jurídicas e metajurídicas. Não é essa a leitura proposta no presente trabalho acerca do tema acesso à justiça. Busca-se, com a presente pesquisa, a análise critica do acesso ao Judiciário como um Direito Fundamental do cidadão debater juridicamente de forma ampla a pretensão e o mérito processual da demanda. A participação do julgador no debate isonômico e jurídico da pretensão constitui corolário da legitimidade democrática do provimento.

A proposta do legislador constituinte no artigo 5, inciso XXXV foi redesenhar o acesso à justiça (acesso ao Judiciário) a partir da superação do entendimento autoritário da ação como um direito cujo exercício fica adstrito à observância das condições da ação ${ }^{11} \mathrm{e}$ dos pressupostos processuais, tal como trabalhado por Bulow, Chiovenda, Carnelutti e Liebman. O acesso ao Judiciário deve ser visto como um Direito Fundamental corolário da cidadania, considerada fundamento do Estado Democrático de Direito ${ }^{12}$. Importante ressaltar que a cidadania, nessa perspectiva, deve ser vista como um direito de participação no processo e, por conseguinte, de participação na construção e no debate do mérito processual.

A relação existente entre direito de ação e acesso ao Judiciário encontra-se diretamente vinculada ao estudo do mérito, tendo em vista que a democratização do acesso ao Judiciário viabiliza o exercício da cidadania no momento em que é assegurado a todos os jurisdicionados o direito de participar efetivamente da construção do mérito processual.

\footnotetext{
${ }^{11} \mathrm{O}$ estabelecimento de condições para a ação, em face do modelo constitucional que amplia o acesso à Justiça, constitui um óbice à apreciação da lesão e da ameaça a direito, ofendendo o Texto Constitucional (MACIEL JUNIOR, 2006, p. 168).

${ }_{12}$ Inspirando-nos nas doutrinas até aqui colacionadas e levando em conta o principio da Supremacia da Constituição, do qual emerge a garantia fundamental do devido processo constitucional, entendemos que, em sentido jurídico amplo, ação, espécie do gênero direito constitucional de petição, é direito assegurado a qualquer pessoa (natural ou jurídica, de direito público ou de direito privado), exercido contra o Estado, consistindo em lhe exigir seja prestada a jurisdição, tendo por base a instauração de um processo legal e previamente organizado segundo o devido processo constitucional, no qual postulará decisão sobre uma pretensão de direito material (Constituição Federal, art. $5^{\circ}$, inciso XXXIV, alínea $a$, e incisos XXXV, LIV e LV) (DIAS, 2010, p. 82).
} 
A partir dos estudos desenvolvidos por Mauro Cappelletti (1988) percebemos a grande complexidade que permeia o estudo do tema acesso à justiça. O autor focaliza seu debate cientifico na necessidade de superação dos obstáculos que muitas vezes inviabilizam o acesso à justiça, tais como, a pobreza e as limitações de natureza econômico-financeira do jurisdicionado. Esclarece, ainda, que o acesso à justiça deve ser assegurado não apenas para tutelar pretensões de natureza essencialmente individual, haja vista que a coletivização das demandas judiciais desencadeou a necessidade de ampliação das vias de acesso à justiça para garantir a proteção dos direitos coletivos. Além disso, verifica-se a extrema preocupação do autor com relação à efetividade do acesso à justiça, especificamente no que tange à viabilização do exercício de direitos às partes a partir do processo e do acesso ao Judiciário.

A legitimação democrática da participação dos sujeitos no processo é considerada o fundamento central do entendimento do mérito participado no processo coletivo. "As diversas manifestações dos interessados, comuns ou divergentes, constituiriam o mérito da demanda coletiva" (MACIEL JUNIOR, 2006, p. 180). Tal afirmação se justifica no sentido de ser o processo o espaço que legitimará a discussão da pretensão coletiva por todos aqueles titulares do direito coletivo que balizará juridicamente a construção do provimento.

O processo coletivo, a partir das proposições teóricas desenhadas pelo Estado Democrático de Direito, deve ser uma espaço de inclusão (não de exclusão) de todos os interessados na pretensão coletiva e no debate do mérito. $O$ processo coletivo é um instituto hábil a legitimar a participação direta e o exercício da cidadania. A própria construção do conceito de cidadania a partir do modelo de processo coletivo democrático decorre da implementação do direito de participação de todos os interessados no provimento. "A demanda coletiva dever ser essencialmente participativa (VIGORITI, 1979, p. 03-16), no sentido de permitir que o maior número de legitimados interessados possa defender suas teses em juízo" (MACIEL JUNIOR, 2006, p. 178).

O cerne de toda a problemática atinente ao acesso amplo e democrático ao Judiciário é viabilizar a participação aberta de todos os legitimados interessados na construção do provimento e do mérito processual, especialmente nas ações coletivas, cuja finalidade é "legitimar essa participação no sentido de que ela represente efetivamente o maior número de interessados no fato ou situação jurídica geradores do conflito coletivo" (MACIEL JÚNIOR, 2006, p. 178). 
Toda essa discussão teórica perpassa pela revisitação da concepção clássica do processo coletivo pensado e construído a partir do sujeito. O acesso ao Judiciário é estreito e limitado quando o processo coletivo é compreendido a partir dessa vertente teórica, uma vez que o legislador é considerado o legitimado a escolher os sujeitos que terão acesso à justiça. Em contrapartida, temos a Teoria das Ações Coletivas como Ações Temáticas, desenvolvida pelo jurista Vicente de Paula Maciel Junior, cujo entendimento do processo coletivo parte do objeto

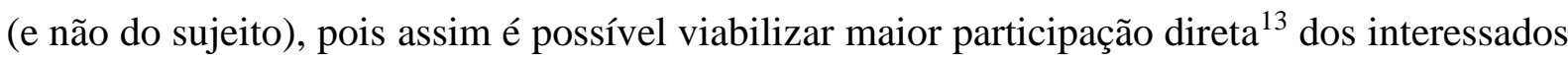
difusos no processo coletivo com a maior ampliação do acesso ao Judiciário. A realização de audiências públicas constitui uma forma legitima de ampliar a participação popular dos legitimados na construção do mérito processual nas ações coletivas, de modo assegurar o amplo acesso à justiça no Estado Democrático de Direito.

\section{O Sistema representativo e a problemática jurídica da legitimidade processual ativa na ação civil pública}

As proposições teóricas que fundamentam o processo coletivo vigente no Brasil são de natureza dogmática e construídas a partir da herança individualista e autoritária do processo civil, cujo entendimento e compreensão advêm do exercício da autoridade e do poder jurisdicional pelo julgador.

A reconstrução dos fundamentos teóricos do processo coletivo se faz necessária para viabilizar a revisitação e a superação da visão privatística do processo coletivo vigente no Brasil. Compreender o processo coletivo pelo viés do processo civil é reconhecer a exclusão dos interessados difusos e coletivos na construção do provimento estatal. Estudar o processo coletivo a partir da concepção teórica preconizada pelos estudiosos do processo civil é o mesmo que reconhecer um modelo de processo através do qual os legitimados processuais serão apenas aqueles sujeitos ou aquelas instituições aleatoriamente escolhidos pelo legislador como aptos à proteção dos direitos coletivos e difusos.

O estabelecimento do rol de legitimados, ou seja, a definição, pelo legislador, de algumas instituições legitimadas à propositura das ações coletivas (ex. Ministério Público) é

\footnotetext{
${ }^{13}$ La participación popular más directa que puede surgir en materia de Justicia y proceso la constituye, sea la designacións de jueces elegidos por voto popular, sistema que se ensaya en las comunidades locales de los Estados Unidos, así como la propia designación (por este medio primero o por otros órganos secundarios en otros casos) de jueces populares, tales como los tribunales de camaradas sociéticos. (VESCOVI, 1988, p. 365).
} 
considerada uma das demonstrações mais claras de que temos uma vertente essencialmente autoritária para o entendimento do processo coletivo. Tal afirmação se justifica inicialmente pelo fato do atual modelo de processo coletivo adotado no Brasil ser distinto teoricamente daquele modelo de processo preconizado e trazido pela Constituição brasileira de 1988.

A base de todo o processo coletivo brasileiro vigente encontra-se no Sistema Representativo. Trata-se de um modelo de processo através do qual o legislador, solitária e unilateralmente, é quem define os legitimados à propositura de uma ação coletiva. A previsão do Sistema Representativo no processo coletivo brasileiro vigente denota a adoção da ideologia perpetrada por uma cognominada assembléia de especialistas, composta por pessoas presumidamente mais preparadas para exercer, em nome dos demais interessados, os direitos coletivos e difusos. Nesse sentido ressalta-se que "[...] com o acesso das massas à justiça, grandes parcelas da população vêm participando do processo, conquanto por intermédio dos legitimados à ação coletiva" (GRINOVER; MENDES; WATANABE, 2007, p. 12-13).

A adoção do Sistema Representativo exterioriza a opção do legislador brasileiro pela legitimidade extraordinária como fator regente de praticamente todo o processo coletivo no Brasil. O artigo $5^{\circ}$ da Lei 7.347/85 (VIGLIAR, 1999, p. 74) traz como legitimados à propositura da ação civil pública o Ministério Público, a Defensoria Publica, os entes da Administração Pública Direta (União, Distrito Federal, Estados e Municípios), os entes da Administração Pública Indireta (Autarquias, Fundações Pública, Empresas Públicas e Sociedades de Economia Mista) e as associações constituídas há pelo menos um ano nos termos da legislação civil brasileira e que inclua entre suas finalidades institucionais a proteção ao meio ambiente, ao consumidor, à ordem econômica, à livre concorrência, ao patrimônio artístico, histórico, turístico, estético e paisagístico.

Pela análise do texto legal que institui a ação civil pública resta claro que o cidadão não é considerado parte legítima para figurar como autor da respectiva ação coletiva, tendo em vista que o legislador optou expressamente pelo Sistema Representativo como fator regente do modelo de processo coletivo adotado no Brasil, limitando-se, assim, o acesso à justiça na perspectiva democrático-participada.

Em contrapartida, verifica-se que a Constituição brasileira de 1988 traz no seu artigo $1^{\circ}$ a soberania popular e a cidadania como um dos fundamentos do Estado Democrático de Direito, ao instituir o principio da participação popular como o parâmetro para o entendimento discursivo-constitucional do modelo de processo coletivo que deve ser adotado no Brasil. 
A institucionalização do Estado Democrático de Direito como a forma de Estado adotada pelo Brasil representa expressamente a intenção do legislador constituinte revisitar e superar o modelo de processo coletivo desenvolvido essencialmente a partir do Sistema Representativo. Pretendeu o legislador constituinte implementar o Sistema Participativo como norte ao entendimento critico do processo coletivo constitucional democrático.

A democratização do processo coletivo pressupõe a revisitação e a superação teórica do Sistema Representativo que dará lugar ao Sistema Participativo, para que todos os interessados difusos e coletivos tenham legitimidade para intervir juridicamente no debate e na construção participada do mérito processual nas ações coletivas.

A Teoria das Ações Coletivas como Ações Temáticas, de autoria do jurista Vicente de Paula Maciel Junior, reconstrói teoricamente todo o processo coletivo ao propor a superação do Sistema Representativo pelo Sistema Participativo. O processo coletivo deixa de ser visto sob o enfoque do sujeito, ou seja, o legislador não tem legitimidade para definir imperativamente quais serão as pessoas ou as instituições legitimadas a propositura de uma ação coletiva de forma genérica e abstrata. $\mathrm{O}$ legislador não poderá definir taxativamente o rol de legitimados à propositura das ações coletivas, tendo em vista que deverá assegurar a todos os sujeitos interessados na pretensão deduzida em juízo o direito de figurar como parte na relação processual ora instituída.

A legitimidade dos interessados difusos e coletivos no debate processual do mérito é auferida na medida em que a análise da pretensão denota que a demanda atinge "um fato e um bem sobre a qual a tutela judicial vai incidir e poder envolver um grande número de interessados" (MACIEL JUNIOR, 2006, p. 173). Nesse mesmo sentido, Vicente de Paula Maciel Junior afirma que "a definição judicial sobre o fato que atinge um número grande de interessados revela que a demanda é coletiva” (MACIEL JUNIOR, 2006, p. 173).

Considerando-se que a cidadania é fundamento do Estado Democrático de Direito e que a noção de cidadania na concepção democrática é construída a partir da implementação dos Direitos Fundamentais, especificamente o direito de participação no processo e o acesso amplo ao Judiciário, a simples demonstração da condição de interessado difuso garante a qualquer sujeito o direito a possibilidade de imiscuir-se no debate jurídico da pretensão e na construção do mérito da demanda coletiva. A exclusão do interessado difuso na construção do provimento materializa a inviabilidade de exercício democrático da cidadania e do acesso à justiça. 


\section{Sistema Participativo, Mérito Processual e Acesso à Justiça no Estado Democrático de Direito}

O processo visto sob a ótica da Teoria Democrática dos Direitos Fundamentais busca institucionalizar o discurso que legitimará o provimento pela participação das partes juridicamente interessadas na argumentação da pretensão deduzida. Nesse sentido, o processo constitucional ${ }^{14}$ deverá ser visto como um recinto que oportuniza o debate amplo da pretensão por todos os interlocutores e interessados na produção do provimento estatal. A participação no processo será regida pelos princípios constitucionais que legitimarão o discurso democrático de construção do provimento, a fim de assegurar: a) a igualdade jurídica de argumentação a todos os sujeitos do processo; b) o direito dos interessados livremente produzirem provas e se utilizarem dos meios de provas licita e legitimamente admitidos em direito; c) a garantia de que as partes não serão surpreendidas por uma decisão unilateralmente imposta pelo julgador que não permite a co-autoria dos destinatários do provimento; d) o direito a uma decisão judicial juridicamente fundamentada e produto da análise, pelo julgador, de todos os temas, as questões e alegações trazidas pelas partes para o processo.

A teorização do estudo do processo no modelo constitucional se justifica na busca da superação do decisionismo judicial decorrente das percepções metajurídicas ${ }^{15}$ do juiz com relação ao julgamento do caso concreto. "O juiz ou o decididor, nas democracias, não é livre intérprete da lei, mas o aplicador da lei como intérprete das articulações lógico-jurídicas produzidas pelas partes construtoras da estrutura procedimental” (LEAL, 2009, p. 63).

\footnotetext{
${ }^{14} \mathrm{O}$ processo lastreado em um modelo constitucional (Andolina, Vignera) constitui a base e o mecanismo de aplicação e controle de um direito democrático. Processo democrático não é aquele instrumento formal que aplica o direito com rapidez máxima, mas, sim, aquela estrutura normativa constitucionalizada que é dimensionada por todos os princípios constitucionais dinâmicos, como o contraditório, a ampla defesa, o devido processo constitucional, a celeridade, o direito ao recurso, a fundamentação racional das decisões, o juízo natural e a inafastabilidade do controle jurisdicional. Todos esses princípios serão aplicados em perspectiva democrática se garantirem uma adequada fruição de direitos fundamentais em visão normativa, além de uma ampla comparticipação e problematização, na ótica policêntrica do sistema, de todos os argumentos relevantes para os interessados (DIAS, 2010, p. 92 apud NUNES, 2008, p. 247-250).

${ }^{15}$ Se colocado o problema de acerto da decisão sob crivos principiológicos assistemáticos, como se as sentenças fossem atos isolados dos juízes, afasta-se também, nesse contexto, a conquista jurídicoteórica do processo (devido processo constitucional) como instituição regente da estruturação dos procedimentos pelo contraditório, ampla defesa, isonomia das partes, direito ao advogado e à movimentação incondicional da jurisdição. Com efeito, a hermenêutica desenvolvida no procedimento processualizado, nas democracias plenas, não se ergue como técnica interpretativa do juízo de aplicação vertical (absolutista) do direito, mas como exercício democrático de discussão horizontal de direitos pelas partes no espaço-tempo construtivo da estrutura procedimental fixadora dos argumentos encaminhadores (preparadores) do provimento (sentença) que há de ser "a conclusão" das alegações das partes e não um ato eloqüente e solitário de realização de justiça (LEAL, 2009, p. 57).(grifo nosso).
} 
A jurisdição no Estado Democrático de Direito não pode ser vista e compreendida como uma atividade pessoal do juiz ou o poder de julgar de forma justa, tendo em vista que se trata de uma "atividade estatal subordinada aos princípios e fins do processo" (LEAL, 2009, p. 66), ou seja, não devemos compreender a jurisdição como uma atividade jurídico-resolutiva e pessoal do juiz, mas o próprio conteúdo da lei conduzido pelos agentes indicados na lei democrática (LEAL, 2009, p. 63).

Submeter o tema jurisdição à reflexão cientifica na seara da constitucionalidade democratizante é perceber que se trata de uma atividade exercida pela principiologia regente do processo (contraditório, ampla defesa, devido processo legal, isonomia processual), de forma compartilhada pelo julgador e todos os demais sujeitos legitimados ao debate processual da pretensão deduzida.

O processo coletivo deve ser resultado da compreensão procedimental e discursiva dos direitos coletivos e difusos, no contexto da participação dos sujeitos interessados como agentes da formação da vontade democrática. O principio básico da democracia é o direito de simétrica participação dos interessados nos processos de formação da vontade e da opinião. É necessário oferecer a todos os interessados iguais condições de participação na construção do provimento. O processo de formação da vontade coletiva deverá ser produto da vontade comum, discursivamente construída pela autonomia argumentativa de cada sujeito interessado na pretensão ou no objeto do debate.

As proposições científicas desenvolvidas pelo jurista Vicente de Paula Maciel Júnior, autor da Teoria das Ações Coletivas como Ações Temáticas, refletem a tentativa de reconstrução do modelo clássico de processo coletivo proposto pela Escola Paulista de Processo, cujo foco de análise concentra-se no sistema representativo e parte de pressuposições teóricas trazidas do processo civil como norte ao entendimento da legitimidade para agir nos direitos coletivos.

A análise científica da legitimação para agir emergiu como o grande foco do debate do processo coletivo, uma vez que a tendência dos estudiosos atualmente é adotar para as ações coletivas o modelo de legitimação anteriormente desenvolvido no processo civil individual. O que o atual modelo de processo coletivo propõe é a escolha dos sujeitos legitimados feita diretamente pelo legislador, ou seja, abstratamente se define quem serão os sujeitos legitimados a propositura de uma ação coletiva. O respectivo modelo é falho no momento em que se verifica 
ser impossível analisar de forma prévia e abstrata quem serão os sujeitos legitimados à demanda coletiva.

Considerando-se que o processo coletivo democrático é o lócus do debate jurídico e amplo da pretensão, serão legitimados ao provimento todos aqueles sujeitos que demonstrarem interesse em participar do discurso jurídico da pretensão. A partir da análise critica do principio democrático no contexto das ações temáticas, o rol de legitimados processuais à propositura de uma ação coletiva sempre deverá ser exemplificativo, ou seja, não se admite e não se reconhece jurídico-constitucionalmente o rol taxativo de legitimados, haja vista que essa é uma forma de legitimar a exclusão dos interessados do debate processual das questões meritórias que integram o objeto da demanda e, assim, restringir o acesso à justiça no Estado Democrático de Direito.

A instauração regular do principio do contraditório no processo coletivo democrático ocorrerá quando for conferida "a possibilidade de titulares de situações subjetivas diversas participarem da demanda ao lado do legitimado ordinário" (MACIEL JUNIOR, 2006, p. 132). Considerando-se que o contraditório é um principio constitucional cuja interpretação deverá ser sistemática e extensiva (nunca restritiva), conclui-se que sua efetividade e aplicação somente será possível quando todos os interessados puderem ser inseridos como sujeitos do debate processual. Para os defensores de um modelo de processo coletivo centrado em bases representativas o contraditório seria exercido por meio de um representante que, em nome do (s) representado (s) teria legitimidade pressuposta e apriorística para a argumentação.

A principal critica que podemos fazer quando se analisa essa problemática cientifica é que o exercício do contraditório por um representante do grupo, da classe ou de toda a coletividade certamente impedirá o esgotamento das questões e dos fundamentos postos em debate causando, por conseqüência, o esvaziamento do discurso democrático em virtude da limitação e da restrição das diretrizes e dos pilares estruturais do principio democrático da participação no processo coletivo.

Reduzir a compreensão do principio do contraditório à representação dos direitos da coletividade por um representante adequado é retirar dos interessados difusos e coletivos o direito de influir na formação do provimento jurisdicional, uma vez que a legitimação para agir no processo coletivo deve ser estendida a todos os protagonistas do processo que sofrerão os efeitos da decisão. 
É nesse contexto do debate cientifico que podemos afirmar que a legitimidade extraordinária no processo coletivo não poderá excluir a participação daqueles sujeitos que serão afetados pelo provimento.

O processo de formação da vontade coletiva decorre de deliberações dos interessados e de um sério e profundo debate em que todas as questões atreladas ao objeto central sejam submetidas à testificação. É por isso que no processo coletivo, compreendido sob o enfoque das ações temáticas, as decisões judiciais não são proferidas exclusivamente a partir do entendimento solipsista do julgador. A formação de uma decisão judicial deve ser reflexo e conseqüência de tudo o que foi posto em discussão pelas partes para, nesse contexto, assegurar efetivamente o amplo acesso à justiça. É certo que a vontade da maioria não reflete e nem representa o interesse de todos os titulares do direito debatido. O provimento jurisdicional coletivo será considerado legitimamente democrático quando todas as questões postas em debate forem levadas em consideração no momento do juiz decidir. Mesmo que o julgador não concorde ou não acate as teses e as alegações suscitadas pelas partes, sabe-se que o contraditório somente se efetivará quando houver manifestação judicial fundamentada acerca de tudo o que foi submetido ao principio do discurso. "Somente por processos reconhecidos válidos pelos indivíduos ou pela lei é que será possível chegar a um consenso que exprima a vontade coletiva" (MACIEL JUNIOR, 2006, p. 154).

\section{Conclusão}

O atual modelo de processo coletivo brasileiro pauta-se no sistema representativo, haja vista que o legislador definiu aprioristicamente os legitimados ativos à propositura da ação civil pública, ressaltando-se que o cidadão foi excluído do respectivo rol, mesmo sabendose que o mesmo sofrerá diretamente os efeitos jurídicos do provimento final. Dessa forma, os interessados difusos e coletivos ficam afastados do debate de mérito nas ações coletivas, cuja decisão é solitariamente proferida pelo magistrado a partir de suas percepções e conclusões obtidas na análise do caso concreto.

A previsão constitucional do sistema participativo (artigo $1^{\circ}$ da Constituição brasileira de 1988) é o fundamento regente para justificar a legitimidade de todos os interessados no debate do mérito processual nas ações coletivas. Foi nesse cenário que o jurista mineiro Vicente de Paula Maciel Junior propôs a Teoria das Ações Coletivas como Ações Temáticas, contraponto ao sistema representativo vigente. Os sujeitos legitimados a 
participar da formação do mérito são definidos casuisticamente a partir das peculiaridades do caso concreto, ou seja, é o objeto da ação coletiva que legitima os sujeitos interessados a apresentar temas pertinentes ao que foi inicialmente alegado, visando democratizar a construção do conteúdo decisório.

Nesse contexto, o processo constitucional democrático é visto como lócus de discursividade ampla, isomênica e isocrítica dos pontos controversos da demanda por todos os interessados, desconstruindo o protagonismo judicial decorrente da legitimidade pressuposta do julgador.

Assim, o acesso à justiça no âmbito da processualidade democrática se efetiva mediante a construção dialógica do mérito processual nas ações coletivas por todos os sujeitos atingidos pelos efeitos do conteúdo do provimento. Adotar o sistema representativo como modelo regente das ações coletivas no Brasil é uma forma de limitar o acesso a justiça, perpetuar o solipsismo judicial e submeter os interessados aos efeitos do provimento final sem assegurar-lhes o direito de participação na sua construção dialética da decisão. A formação participada do mérito processual nas ações temáticas evita o cerceamento de defesa e assegura o devido processo legal a todos os sujeitos interessados no momento em que implementa amplamente direito constitucional de ação.

\section{Referências}

BASTOS, José Timóteo da Silva. Diccionário Etymológico, Prosódico e Orthográphico da Lingua Portuguesa. São Paulo, 1928.

BEZERRA, Paulo César Santos. Acesso à Justiça: um problema ético-social no plano da realização do direito. Rio de Janeiro: Renovar, 2001.

CALAMANDREI, Piero. Estudios sobre el proceso civil. Traduccion:Santiago Sentis Melendo. Buenos Aires: Editorial Bibliográfica Argentina, 1945.

CALAMANDREI, Piero. Direito Processual Civil. v. I. Tradução: Luiz Abezia e Sandra Drina Fernandez Barbery. Campinas: Bookseller, 1999-a.

CAPPELLETTI, Mauro; GARTH, Bryant. Acesso à Justiça. Tradução Ellen Gracie Northfleet. Porto Alegre: Sérgio Antônio Fabris Editor, 1988.

CARNELUTTI, Francesco. Teoria del regolamento colletivo: dei rapporti di lavori. Padova: CEDAM, 1930. 
CARNELUTTI, Francesco. Lezioni di diritto processuale civil: processo di esecuzione.

Padova: CEDAM, 1932.

CARNELUTTI, Francesco. Sistema di diritto processuale civile. Padova: CEDAM, 1936.

CARNELUTTI, Francesco. Studi di Diritto Processuale. Padova: CEDAM, 1939.

CARNELUTTI, Francesco. Instituzioni del nuovo proceso civile. Roma: Soc. Ed. Del Foro Italiano, 1951.

CARNELUTTI, Francesco. Teoria general del diritto. Roma: Soc. Ed. Del Foro Italiano, 1951.

CARNELUTTI, Francesco. Sistema de Direito Processual Civil. v. I. Tradução: Hiltomar Martins Oliveira. 1. ed. São Paulo: ClassicBook, 2000-a.

CARNELUTTI, Francesco. Teoria Geral do Direito. Rio de Janeiro: Âmbito Cultural, 2006.

CHIOVENDA, Giuseppe. Istituzioni di Diritto Processuale Civile. v. I. 2. ed. Napoli: Casa

Editrice Dott Eugenio Jovene, 1960.

CHIOVENDA, Giuseppe. Instituições de Direito Processual Civil. Tradução: J. Guimarães Menegale. 3. ed. São Paulo: Saraiva, 1969.

CHIOVENDA, Giuseppe. Instituições de Direito Processual Civil. v. I. Tradução: Paolo Capitanio. 3. ed. Campinas: Bookseller, 2002-a.

DIAS, Ronaldo Brêtas de Carvalho. Processo Constitucional e Estado Democrático de Direito. Belo Horizonte: Del Rey, 2010.

DINAMARCO, Cândido Rangel. Fundamentos do Processo Civil Moderno. São Paulo: Revista dos Tribunais, 1986.

DINAMARCO, Cândido Rangel. Fundamentos do Processo Civil Moderno. 2. ed. São Paulo: Revista dos Tribunais, 1987.

DINAMARCO, Cândido Rangel. Escopos Políticos do Processo. Participação e Processo. Coordenação: Ada Pellegrini Grinover, Cândido Rangel Dinamarco e Kazuo Watanabe. São Paulo: Revista dos Tribunais, 1988.

GRINOVER, Ada Pellegrini; MENDES, Aluisio Gonçalves de Castro; WATANABE, Kazuo. Direito Processual Coletivo e o anteprojeto de Código brasileiro de Processos Coletivos. São Paulo: Revista dos Tribunais, 2007.

LEAL, Rosemiro Pereira. Teoria Geral do Processo - Primeiros Estudos. 8. ed. Rio de Janeiro: Forense, 2009. 
LIEBMAN, Enrico Tullio. Estudos sobre o processo civil brasileiro. São Paulo: Bestbook Editora Distribuidora Ltda, 2001.

LIEBMAN, Enrico Tullio Liebman. Manual de Direito Processual Civil. v. 1 3. ed. São Paulo: Malheiros, 2003.

MACIEL JUNIOR, Vicente de Paula. Teoria das Ações Coletivas: as ações coletivas como ações temáticas. São Paulo: Ltr, 2006.

MADEIRA, Dhenis Cruz. Reflexões Propedêuticas sobre o mérito no processo civil. Direito Processual Reflexões Jurídicas. Coordenadores: João Antônio Lima Castro e Sérgio Henriques Zandona Freitas. Belo Horizonte: PUC Minas, Instituto de Educação Continuada, 2010.

VIGLIAR, José Marcelo Menezes. Ação Civil Pública. 3. ed. São Paulo: Atlas, 1999.

VIGORITI, Vincenzo. Interessi Collettivi e Processo - la legittimazione ad agire. Milano:

Dott A. Giuffré Editore, 1979.

WAMBIER, Luiz Rodrigues; ALMEIDA, Flávio Renato Correia de; TALAMINI, Eduardo. Curso Avançado de Processo Civil - Teoria Geral do Processo e Processo de Conhecimento. 7. ed. ver. e atua. São Paulo: Revista dos Tribunais, 2005.

WAMBIER, Luiz Rodrigues; ALMEIDA, Flávio Renato Correia de; TALAMINI, Eduardo. Curso Avançado de Processo Civil - Teoria Geral do Processo e Processo de Conhecimento. 10. ed. ver. e atua. São Paulo: Revista dos Tribunais, 2008.

WATANABE, Kazuo. Da cognição no Processo Civil. São Paulo: Revista dos Tribunais, 1987.

WATANABE, Kazuo. Acesso à Justiça e Sociedade Moderna. Participação e Processo. Coordenação: Ada Pellegrini Grinover, Cândido Rangel Dinamarco e Razuo Watanabe. São Paulo: Revista dos Tribunais, 1988.

WATANABE, Kazuo. Da Cognição no Processo Civil. 3. ed. rev. e atual.São Paulo: DPJ, 2005. 